\title{
INFORMÁTICA COMO INSTRUMENTO PARA INTERDISCIPLINARIDADE
}

\author{
Marcos Antonio Gomes Xavier \\ Mediador Pedagógico Presencial na Fundação Centro de Ciências e Educação Superior a Distância do \\ Estado do Rio de Janeiro. Especialista em Tecnologias, Formação de Professores e Sociedade. \\ https://orcid.org/0000-0001-5898-416X
}

Data de submissão: 05/08/2020

Data de aprovação: 02/10/2020

\section{RESUMO}

Este artigo traz com detalhes a elaboração da proposta de projeto interdisciplinar para curso de nível superior na modalidade híbrida, tendo como principal pilar do projeto o uso da tecnologia no processo ensino-aprendizagem no ambiente virtual de aprendizagem. A problemática está em viabilizar a utilização da tecnologia como instrumento para interdisciplinaridade, tendo como objetivo central a realização do planejamento de um projeto educacional, em especial para disciplina de Introdução à Informática, utilizando as novas tecnologias digitais de informação e comunicação como instrumento na prática de atividades interdisciplinares e visando melhor desempenho na vida cotidiana e acadêmica de alunos e tutores. Para tal, a metodologia principal utilizada foi a de Projeto, que está envolvida com métodos de coordenar e controlar alguns tipos de atividades complexas e dinâmicas, diferenciando-se muito da administração tradicional de atividades de rotina. A base de dados é do segundo semestre de 2018, com foco no curso de Administração Pública que teve 68 cursistas matriculados na disciplina de Introdução à Informática. Por fim, concluiu-se, que a implementação das fases Iniciação e de Planejamento do Projeto Interdisciplinar para as disciplinas envolvidas transcorreram perfeitamente dentro do prazo estipulado de dois meses, atingindo todas as metas, graças ao engajamento dos colaboradores da equipe do Projeto Interdisciplinar para a disciplina de Introdução à Informática, que é ofertada no primeiro período para todos os cursos de nível superior do Consórcio do Centro de Educação Superior a Distância do Estado do Rio de Janeiro.

Palavras-chave: Informática. Interdisciplinaridade. Ambiente virtual de aprendizagem. Tecnologia.

\section{INFORMATICS HOW INSTRUMENT TO INTERDISCIPLINARITY}

\section{ABSTRACT}

This article details the elaboration of the interdisciplinary project proposal for a higher education course in hybrid mode. The main pillar of the project is the use of technology in the teaching-learning process in the virtual learning environment. The problem is in the use of technology as an instrument for interdisciplinarity. The main objective is to carry out the planning of an educational project, especially for the Introduction to Informatics discipline. Using the new digital information and communication technologies as an instrument in the practice of interdisciplinary activities. Aiming at the best performance in everyday and academic life. of students and tutors. For this, the main methodology used was that of Project, which is involved with methods of coordinating and controlling some types of complex and dynamic activities, differing a lot from the traditional administration of routine activities. The database is from the second semester of 2018, focusing on the Public Administration course, which had 68 students enrolled in the Introduction to Informatics 
course. It was concluded that the implementation of the Initiation and Planning phases of the Interdisciplinary Project for the disciplines involved took place perfectly within the stipulated period of two months, reaching all goals, thanks to the engagement of the Interdisciplinary Project team collaborators for the Introduction discipline to Informatics, which is offered in the first period for all higher education courses from the Consortium of the Center for Higher Education at Distance in the State of Rio de Janeiro.

Keywords: Computing. Interdisciplinarity. Virtual learning environment. Technology.

\section{LA INFORMÁTICA COMO INSTRUMENTO DE INTERDISCIPLINARIDAD}

\section{RESUMEN}

Este artículo detalla la elaboración de la propuesta de proyecto interdisciplinario de un curso de educación superior en modalidad híbrida, teniendo como pilar principal del proyecto el uso de la tecnología en el proceso de enseñanza-aprendizaje en el ambiente virtual de aprendizaje. El problema es posibilitar el uso de la tecnología como instrumento de interdisciplinariedad, con el objetivo central de llevar a cabo la planificación de un proyecto educativo, especialmente para la disciplina de Introducción a la Informática, utilizando las nuevas tecnologías digitales de la información y la comunicación como instrumento en la práctica de actividades interdisciplinares y con el objetivo de un mejor desempeño en la vida diaria y académica de estudiantes y tutores. Para ello, la principal metodología utilizada fue el Proyecto, que se involucra con métodos de coordinación y control de algunos tipos de actividades complejas y dinámicas, diferenciándose mucho de la tradicional administración de actividades rutinarias. La base de datos es del segundo semestre de 2018, con foco en el curso de Administración Pública, que contó con 68 alumnos matriculados en el curso de Introducción a la Informática. Finalmente, se concluyó que la implementación de las fases de Iniciación y Planificación del Proyecto Interdisciplinario para las disciplinas involucradas se desarrolló a la perfección en el plazo estipulado de dos meses, alcanzando todas las metas, gracias al involucramiento de los colaboradores del equipo del Proyecto Interdisciplinario para la asignatura de Introducción a la Informática, que se ofrece en el primer período para todos los cursos de educación superior en el Consórcio do Centro de Educação Superior a Distância do Estado do Rio de Janeiro.

Palabras clave: Informática. Interdisciplinariedad. Ambiente de aprendizaje virtual. Tecnología.

\section{INTRODUÇÃO}

A partir dos relatos das experiências vividas pelos discentes, de um curso de pósgraduação de Tecnologias, Formação de Professores e Sociedade (TFPS), mais especificamente, numa atividade no Ambiente Virtual de Aprendizagem (AVA) - Plataforma Moodle/CEDERJ - Consórcio do Centro de Educação Superior a Distância do Estado do Rio de Janeiro, intitulada postagens na parede digital, notou-se a influência do uso das tecnologias na formação do cursista da modalidade Educação a Distânciai (EaD), em especial, no que tange a sua rotina individual de estudos, que requer ter certo grau de dedicação, compromisso, disciplina e organização, e por consequência desenvolve e aprimora características pessoais e profissionais, extremamente valiosas, como por exemplo: possuir fluência tecnológica e linguística, estar adaptado a mudanças, além das 
capacidades de assimilação; reflexão; criatividade; clareza de raciocínio; motivação e foco (TECNOLOGIAS TFPS, 2018).

Diante do contexto, segundo Xavier et al. (2019, p. 5) onde "sempre que um novo desafio, uma nova proposta ou uma nova situação emerge" no trabalho, "nos remete ao repensar ou reformular as nossas próprias práticas". Então, surge a motivação da elaboração de um Projeto Interdisciplinar para a Disciplina de Introdução à Informática (PIDII), pois a mesma é ofertada no $1^{\circ}$ (primeiro) período para todos os cursos de nível superior do CEDERJ, e contempla no seu conteúdo programático da disciplina o tema Plataforma CEDERJ, ou seja, é o momento onde o cursista tem o primeiro contato com o AVA e suas ferramentas educacionais. Cabe ressaltar que, o AVA é o principal recurso tecnológico a ser utilizado durante a vida acadêmica do cursista, no CEDERJ, por ser o ambiente que contém todos os conteúdos, informações e atividades, por cursos/disciplinas, para que o cursista venha a estabelecer a sua rotina individual de estudos.

A interdisciplinaridade surgi "como uma possibilidade de romper os limites inerentes à divisão em disciplinas, propondo diversos níveis de integração do conhecimento". A interdisciplinaridade "acontece da necessidade sentida pelos professores e alunos de explicar, compreender, intervir, mudar, prever algo que desafia uma disciplina isolada e atrai a atenção de mais de um olhar, talvez vários" (MOUSINHO, 2018, p.1).

O principal pilar do PIDII está no uso das tecnologias no processo ensinoaprendizagem durante a formação dos cursistas, alguns futuros professores (Cursos de Licenciaturas vide Tabela 2). Em outras palavras, o PIDII tem como ponto central a utilização da informática como instrumento para interdisciplinaridade, englobando o máximo de disciplinas dos cursos do CEDERJ durante a Tutoria Prática que aborda uma parte do conteúdo programático da disciplina de "Introdução à Informática".

Neste cenário, para realização da Tutoria Prática é primordial um roteiro das atividades práticas, que deve acontecer somente dentro do laboratório de informática do Polo de Apoio Presencial (PAP), a ser definido no plano de aula, pelos professores, tutores e equipe pedagógica, que vise gerar pelo menos um produto final (arquivo digital) por alguma aplicação, tendo como foco o(s) tema(s) da(s) outra(s) disciplina(s) a ser(em) desenvolvido(s) pelos alunos, com auxílio das novas Tecnologias Digitais de Informação e Comunicação (NTDICs) e com apoio/orientação do tutor presencial da disciplina de "Introdução à Informática".

O PIDII teve como objetivo geral, para o ano de 2018, a realização do planejamento do projeto para o Curso de Administração Pública e futuramente implementar o projeto, inclusive nos diversos cursos de nível superior na modalidade híbrida, que utilizasse as NTDICs como instrumento eficiente e eficaz na prática de atividades interdisciplinares, visando o melhor desempenho na vida cotidiana e acadêmica de alunos e tutores. Como objetivos específicos: promover a capacitação para o uso das NTDICs que auxilie a produzir e gerenciar conhecimentos; consolidar o aprendizado dos conceitos adquiridos; provocar a experiência de propor mudanças de melhorias na administração do PAP em Campo Grande (CGR); conhecer a capacidade dos cursistas na prática dos recursos básicos das ferramentas do LibreOffice.

A proposta de implementação do projeto interdisciplinar (PIDII), nos cursos do CEDERJ (híbrida - modalidade da EaD), possibilita aos alunos (a maioria, futuros professores) e aos tutores presenciais, a quebra de paradigmas, haja vista que anteriormente parecia existir uma preocupação apenas com o contexto da área em formação. Porém, felizmente, vislumbram-se novos olhares sobre a forma de pensar um objeto de estudo, principalmente a partir do despertar do trabalho em equipe, tornando as práticas em sala de tutoria momentos de debates, reflexões e possibilidades de intercambiar diferentes perspectivas sobre diversos temas. 
Para Angélica (2018), o professor, geralmente, na construção de sua historicidade não teve um referencial interdisciplinar em seu desenvolvimento escolar. A autora afirma ainda que "Nos cursos de licenciatura, por exemplo, a metodologia da interdisciplinaridade é abordada para discutir conceitos teóricos e muitas vezes não se elabora nenhum projeto interdisciplinar, nem mesmo nos programas de estágios" (ANGÉLICA, 2018, p.1).

Outro ponto relevante, a ser considerado como pré-requisito para o PIDII, é que os alunos de cursos, na modalidade EaD, híbrida, do consórcio CEDERJ, devem adquirir autonomia na sua aprendizagem e, como boa parte da informação disponível para o curso e da comunicação entre alunos, tutores e coordenadores é feita através da Plataforma CEDERJ, torna-se assim necessário familiarizar o aluno com as NTDICs, visando fortalecer a interação entre os atores envolvidos no processo ensino-aprendizagem na plataforma CEDERJ. Neste contexto do uso das NTDICs surge a oportunidade de utilizar o LibreOffice, que faz parte do currículo da disciplina Introdução à Informática, no PIDII, e é um pacote de aplicativos que auxiliará o aluno não somente na disciplina de Introdução à Informática, mas também no decorrer de todas as disciplinas dos cursos ofertados na modalidade híbrida consórcio CEDERJ.

\section{REFERENCIAL TEÓRICO}

\subsection{Educação à distância}

O Brasil, país de dimensões continentais, tem investido na implementação da educação à distância, por ser um projeto viável e capaz de solucionar, ou pelo menos minimizar, a desproporção que existe atualmente entre a elevada demanda - quantidade de pessoas para serem educadas, e a baixa oferta - quantidade de instituições de ensino (infraestrutura física) disponível e o contingente de educadores capacitados, por região.

A educação à distância é uma modalidade de ensino que amplia as possibilidades do saber, criando e potencializando competências de uma sociedade norteada pela informação.

Se observarmos suas características, que se baseia tanto na noção de distância física/geográfica entre professor e aluno, como na flexibilidade do tempo e localização do aluno em diferentes espaços, veremos que por ser aparentemente nova e em desenvolvimento, a educação à distância é normalmente confundida com o ensino presencial, transpondo ou fazendo adaptações de concepções dessa modalidade tradicional para a educação à distância, gerando uma crise de identidade. Crise que promove questões fundamentais de reflexão e definição da educação à distância (XAVIER, 2016).

Com a Lei de Diretrizes e Bases da Educação - Lei 9.394, de 20 de dezembro de 1996, a educação à distância tem respaldo legal e com os decretos seguintes regulamentam os aspectos variados no que tange a esse tipo de modalidade de educação (BRASIL, 1996).

Aspectos tais como credenciamento institucional, supervisão, acompanhamento e avaliação, são consonantes com a qualidade exigida pelo Ministério da Educação. De qualquer modo, entre muitas iniciativas para melhoria da educação no país encontramos desafios semelhantes em ambas as modalidades de ensino, presencial ou à distância. Entretanto, há se enfatizar que

A Educação a Distância ultrapassa as fronteiras da contraposição à educação presencial e amplia-se para uma perspectiva de comunicação múltipla entre sujeitos em ambientes distintos, promovida a partir de um processo sistemático de trocas e assistência permanente. Assim, se até então as condições para essa interação múltipla se restringiam à presença física dos atores envolvidos, por meio da 
telemática passou a ser possível construir ambientes virtuais de interação multidirecional, que promovem a colaboração e a cooperação entre os sujeitos envolvidos, embora preservando a característica básica de o aluno ser o protagonista de seu próprio aprendizado, a partir de suas especificidades e seu ritmo individual (VILLARDI; OLIVEIRA, 2005, p. 55).

A Educação a Distância tem como um dos desafios atender melhor à relação espaço físico e temporal. Para construir a aprendizagem de forma individual e coletiva apoia-se, fundamentalmente, nos meios de comunicação e na tecnologia, ao mesmo tempo em que socializa e democratiza a educação (XAVIER, 2016).

Dá oportunidades infinitas para diferentes grupos populacionais ao mesmo tempo que proporciona o progresso do homem e da sociedade. Desta forma, a infraestrutura tecnológica, as instalações físicas e de recursos humanos, mostram-se essenciais para contribuir na qualidade da educação à distância.

Diante disso, garantir efetivamente o pleno desenvolvimento das atividades dos cursos à distância, oferecendo "condições e serviços adequados e suficientes para atender aos atores envolvidos em suas expectativas, demandas e necessidades, requer um espaço bem projetado, quando surge a proposta do Polo de Apoio Presencial" (XAVIER, 2016).

\subsection{Polo de apoio presencial}

Segundo Ribas, Moreira e Catapan (2011) são os Polos de Apoio Presencial (PAPs), distribuídos geograficamente, que possibilitam uma quantidade enorme de pessoas a estudar, se atualizar, mesmo estando distante da Instituição Pública de Ensino Superior (IPES).

O Polo de Apoio Presencial (PAP) constitui o "braço operacional" da IPES na cidade do estudante (ou na mais próxima dele), segundo Ribas, Moreira e Catapan (2011), se tornando um elemento primordial para a EaD e para a viabilização da mesma, pois visa o acompanhamento, a orientação dos cursistas e seu desenvolvimento, disponibilizando e favorecendo as práticas laboratoriais.

Os polos têm como finalidade "oferecer o espaço físico de apoio presencial aos alunos da sua região, mantendo as instalações físicas necessárias para atender aos alunos em questões tecnológicas, de laboratório, de biblioteca, entre outras" (NEAD, 2018, p.1).

Cabe ressaltar que, neste cenário, por mais que exista uma proposta de estrutura básica formalmente definida para um PAP pela UAB, que objetiva atender as especificidades básicas de um curso na modalidade da educação à distância, é possível existir edificação de Polo com infra-estrutura diferente, que venha ofertar diversos cursos com estruturas diferentes, que requerem determinados recursos como equipamentos, a serem oferecidos e especificados pelas IES que administram esses cursos no polo (UAB/CAPES, 2018).

\subsection{Gestão do PAP}

O Decreto no 5.800/2006, institui o Sistema Universidade Aberta do Brasil (UAB), com a finalidade de "expandir e interiorizar a oferta de cursos e programas de educação superior no País", por meio do desenvolvimento de programas e de cursos na modalidade de educação a distância. Dentre as diversas questões, formalmente definida e disciplinada pela $U A B$, se destaca a gestão do PAP que está diretamente ligada à sua estrutura, onde o êxito do Sistema depende de seu bom funcionamento, para tal requer gestores capacitados, que garanta uma estrutura administrativa e pedagógica adequada para atendimento ao seu público. Nesse contexto, Bergue (2012, p. 17-23) relata que 
a existência das organizações está relacionada à distribuição e execução de tarefas, e que isso se dá por intermédio das pessoas, que por sua vez não se dissociam de suas escalas sociais de valores éticos" e que a "cultura é algo que permeia a estrutura, os processos e as pessoas de uma organização, interferindo de forma determinante no seu desempenho.

O Coordenador (termo semelhante a gestor ou administrador) do PAP é um "professor da rede pública, graduado e com, no mínimo, 3 (três) anos em magistério na educação básica ou superior", conforme consta na Resolução CD/FNDE $N^{\circ} 26$ (UAB/CAPES, 2018). Na Portaria no 153 são definidas as funções do Coordenador do PAP, onde destaca-se a seguinte: "articular-se com o mantenedor do polo com o objetivo de prover as necessidades materiais, de pessoal e de ampliação do polo" MEC (2018).

Então, o que se espera do Coordenador de PAP é que venha exercer suas funções, em conformidade com o Modelo de Gestão PEAC: Planejamento; Execução; Avaliação e Controle (ilustrado na Figura 6), com o intuito de atingir os objetivos propostos pela organização (MALMEGRIN, 2012).

Planejamento - "a etapa visa a fornecer orientações diretivas, definindo metas ou normativas, métodos, técnicas e ferramentas para que a próxima etapa de execução seja realizada".

Execução - "a etapa compreende as atividades preparatórias para capacitar as pessoas, educando-as e treinando-as, a fim de que sejam capazes de executar o que foi programado na etapa de planejamento". "A etapa de execução gera produtos, também denominados resultados, e sobre esses produtos e o modo como foram obtidos serão coletados dados relevantes da etapa".

Avaliação - "tem como objetivo fornecer dados para a próxima etapa, o controle, comparando o que foi planejado com o que foi realizado; valorando os desvios encontrados e identificando as respectivas causas; e, até mesmo, sugerindo alternativas de caminhos para que, o que foi planejado, volte a ser executado e os produtos e os resultados sejam obtidos".

Controle - "a última etapa, tem caráter decisório e executivo, pois contempla atividades não somente de tomada de decisão acerca de como corrigir as disfunções apontadas na etapa de avaliação e, às vezes, de como rever o planejamento anterior, papel preventivo, mas, também, executando as ações corretivas e de melhorias" (MALMEGRIM, 2012, p. 13).

Figura 1 - Do Ciclo PDCA ao Ciclo PEAC

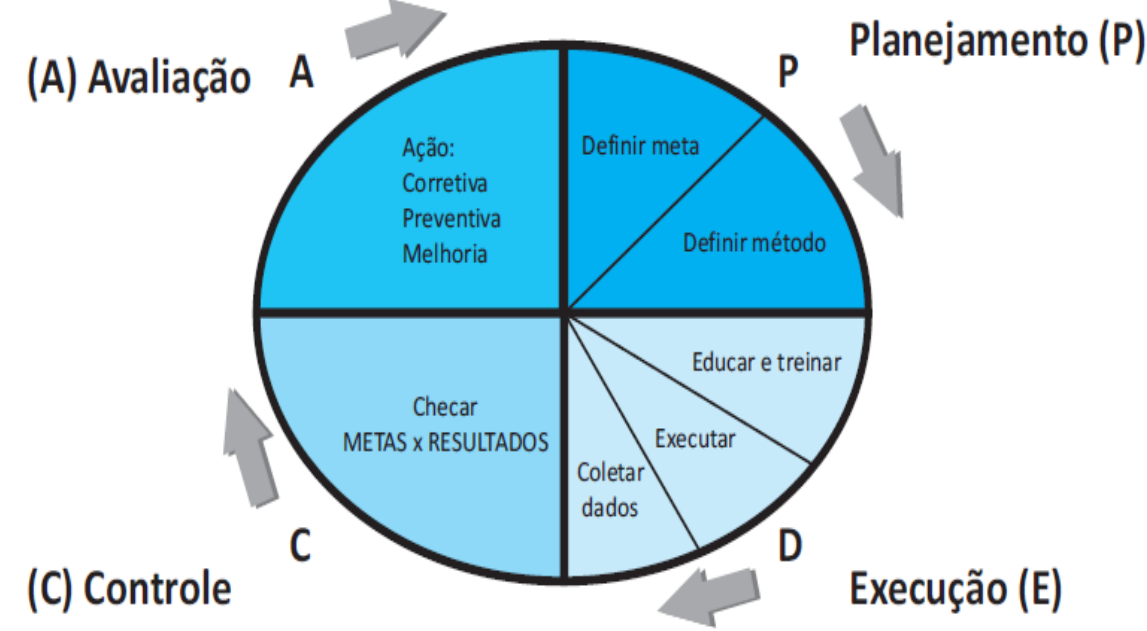

Fonte: Malmegrin (2012). 


\subsection{Tutoria presencial}

O Consórcio CEDERJ, ao implementar a metodologia de educação à distância, permite o acesso, ao ensino superior público, para as pessoas que moram longe das universidades ou por indisponibilidade de tempo nos horários tradicionais de aula (CECIERJ, 2018).

Os cursos de graduação a distância ofertados pelo Consórcio CEDERJ permitem que o aluno estude no local e horário de sua preferência, seguindo um cronograma e um plano de estudo, para cada disciplina (CECIERJ, 2018).

No entanto, algumas disciplinas (exemplo: a "Introdução à Informática") exigem um número mínimo de presença no polo para a execução das aulas práticas de laboratório. Para isso, o aluno conta com o apoio de tutoria presencial, nos próprios PAP.

Cabe ressaltar que, neste cenário, existe uma influência do uso das tecnologias na formação do cursista da modalidade $\mathrm{EaD}$, em especial, no que tange à sua rotina individual de estudos, que tem certo grau de dedicação, compromisso, disciplina e organização, e por consequência desenvolve e aprimora características pessoais e profissionais, extremamente valiosas como, por exemplo: possuir fluência tecnológica e linguística está adaptado a mudanças, além das capacidades de assimilação; reflexão; criatividade; clareza de raciocínio; motivação e foco.

Diante do contexto é importante conhecer todas as 23 (vinte e três) atribuições exigidas, pelo Consórcio CEDERJii, para exercer o cargo de Tutor Presencial (TP). Cabe destacar algumas dessas atribuições TP, pois são de estrema relevância no processo de acolhimento e adaptação dos alunos "calouros", os quais, em sua maioria, desconhecem a modalidade $\mathrm{EaD}$ híbrida, nos primeiros períodos letivos, visando principalmente a autonomia de aprendizagem e respectivamente a redução da evasão por causa da metodologia da educação à distância, como segue:

$\checkmark$ Orientar 0 aluno, através da prática, para a metodologia da educação a distância, enfatizando a necessidade de se adquirir autonomia de aprendizagem.

$\checkmark$ Assistir o estudante, individualmente ou em grupo, visando orientá-lo para a construção de uma metodologia própria de estudo.

$\checkmark$ Trabalhar o material didático com o aluno, individualmente ou em grupo, visando orientá-lo para a construção de uma metodologia própria e autônoma de estudo.

Outrossim, em relação às atribuições que são pré-requisitos fundamentais na tutoria em que ocorre o uso rotineiro das tecnologias na formação do cursista da modalidade EaD, cabe ao tutor:

$\checkmark$ Conhecer as ferramentas de apoio oferecidas para as disciplinas em que atua, orientando os estudantes para o uso dessas ferramentas.

$\checkmark$ Orientar os alunos nas aulas de laboratório, aulas práticas ou trabalhos em grupo, realizados aos sábados e estabelecidos pela coordenação de disciplina.

$\checkmark$ Incentivar os estudantes a participarem das atividades oferecidas pelas disciplinas em que atuam tanto as presenciais quanto as oferecidas na plataforma.

\subsection{Interdisciplinaridade}

As práticas interdisciplinares, historicamente, se originaram na "França nas últimas décadas do século XIX, pela necessidade de dar respostas ao conhecimento e o saber fragmentado provocado obviamente pela concepção positivista", oriundo da subdivisão que as ciências sofreram naquele período (COSTA, 2015, p. 3). Nesse período constatou-se que, "uma fragmentação das ciências humanas e sociais fizeram com que docentes, 
pesquisadores e demais curiosos do conhecimento, hoje encontrem dificuldades para difundir o conhecimento. Daí, a necessidade de se investir na interdisciplinaridade como forma de aproximar diferentes saberes" (COSTA, 2015, p. 3).

No Brasil, é importante ressaltar que, a interdisciplinaridade começa ter influência nas ações dos educadores com a promulgação da Lei de Diretrizes e Base da Educação. "Desde então, coordenadores pedagógicos, docentes e pesquisadores não tem medido esforços, no sentido de fazer com que à educação possa se configurar em uma ação múltiplas de possibilidades no que tange a redução da fragmentação do conhecimento sistematizado" (COSTA, 2015, p. 3).

Pombo (2006, p.3) afirma que, existe uma enorme tradição, no Brasil, com o trabalho interdisciplinar, que em termos de experiências, os primeiros registros iniciam em 1960

[...] com Vieira e Durval (1965), Freitag-Rouanet, (1991) e Fazenda (1998), oferecem elaboradas descrições das mais significativas experiências, entretanto realizadas; em termos de investigação, ainda nos anos setenta, recordaria apenas Lruyten, (1973) e Japiassu (1976). Depois, a partir dos anos 90, Paviani (1993), Lück (1994), Carneiro Leão (1992), Portela (1992), Falenda (2002), Paviani e Botomé (2003). (POMBO, 2006, p. 3).

A interdisciplinaridade surge "como uma possibilidade de romper os limites inerentes à divisão em disciplinas, propondo diversos níveis de integração do conhecimento" (MOUSINHO, 2018, p.1). Fazenda (2011) afirma que a interdisciplinaridade "não é uma categoria de conhecimento, mas sim de ação", portanto podemos nos referir à interdisciplinaridade como uma atitude nova perante do ato de conhecer.

De acordo com Umbelino e Zabini (2014, p. 6), a interdisciplinaridade tem como objetivo "englobar o máximo de disciplinas que possam contribuir com o conteúdo a ser desenvolvido com determinada turma, além de despertar na comunidade escolar um trabalho conjunto, possibilitando uma visão holística dos conteúdos partindo do conhecimento prévio do aluno".

Da mesma forma, visa a promoção de momentos de formação conjunta e de planejamento coletivo, envolvendo todos da equipe da Instituição de ensino (dirigente, coordenadores, supervisores, professores, etc.), para que se possa, por meio do compartilhamento constante da concepção de educação e de estratégias de concretizá-la, efetivar a apropriação na prática.

Lobo Neto (2009) aborda o efeito da ausência da prática na teoria e vice-versa: "A ausência da prática na teoria compromete a sintonia das transformações possíveis e sua evolução". O autor afirma ainda que "a ausência da teoria na prática compromete a possibilidade das práxis e, portanto, de sua força transformadora".

Em outras palavras, segundo Umbelino e Zabini (2014, p. 4), a interdisciplinaridade propõe uma forma de construção do conhecimento que "implica em uma troca de teorias e metodologias, produzindo então novos conceitos, tratando-se a importância de averiguar a pertinência e a relevância das diversas áreas do conhecimento a serem ensinados e estimulados no currículo escolar". Portanto, a interdisciplinaridade possibilita aos futuros professores a quebra de paradigmas, extrapolando o caráter

[...] antes preso somente ao contexto da área em formação, para novos olhares sobre a forma de pensar um objeto de estudo, principalmente no despertar do trabalho em equipe, tomando as práticas em sala de aula momentos de debates, reflexões e olhares diferentes sobre temas como diversidade cultural (UMBELINO; ZABINI, 2014, p. 7).

A interdisciplinaridade é uma proposta de romper com a fragmentação das disciplinas, das ciências e do conhecimento, ou seja, ela surge como um dos caminhos propícios, tanto para romper o isolamento das disciplinas da estrutura curricular, como para reinstalar o trabalho coletivo, em torno do estudo da realidade (UNIVESP, 2011). 
O professor é o grande articulador para garantir a mobilização dos saberes, o desenvolvimento do processo e a realização de projetos, nos quais os alunos estabelecem conexões entre o conhecimento adquirido e o pretendido com a finalidade de resolver situações-problema, em consonância com suas condições intelectuais, emocionais e contextuais (PINHEIRO; SILVEIRA; BAZZO, 2007, p. 77).

Cabe principalmente ao educador, em todos os níveis do ensino, fomentar a construção no espaço escolar da prática interdisciplinar. Fazenda (1994), assinala que

A metodologia interdisciplinar requer uma atitude especial ante o conhecimento que se evidencia no reconhecimento das competências, incompetências, possibilidades e limites da própria disciplina e de seus agentes, no conhecimento e na valorização suficientes das demais disciplinas e dos que a sustentam. (FAZENDA, 1994 p. 69).

Entretanto, mexer na zona de conforto dos docentes pode provocar inquietação, insegurança e até medo. Em relação a este contexto Luck descreve que

No estabelecimento de um trabalho de sentido interdisciplinar provoca, como toda ação a que não se está habituado, uma sobrecarga de trabalho, um certo medo de errar, de perder privilégios e direitos estabelecidos. A orientação pelo enfoque interdisciplinar para a prática pedagógica implica em romper hábitos $e$ acomodações, implica em buscar algo novo e desconhecido. É certamente um grande desafio. (LUCK, 2001, p. 68 apud COSTA, 2015, p.13).

Pombo (2006, p. 13) afirma que, "só há interdisciplinaridade se somos capazes de partilhar o nosso pequeno domínio do saber, se temos a coragem necessária para abandonar o conforto da nossa linguagem técnica e para nos aventurarmos num domínio que é de todos e de que ninguém é proprietário exclusivo".

Segundo Angélica (2018), ressalta-se ainda que, atualmente, é esperado que, o professor esteja atualizado e seja um profissional que supere aquele licenciado e especialista num tema.

Costa (2015) descreve um cenário mais atual, onde "com o mundo cada vez mais interconectado,"

[...] interdisciplinarizado, e complexo, necessitando, portanto, de docentes que possam ver o conhecimento não como uma ação isolada, singularizada, desconectada, mas sim, um mundo plural, onde seja possível debater ideias, trocar experiências e interdisciplinarizar os diferentes saberes presentes nas diversas áreas do conhecimento (COSTA, 2015, p. 12).

Enfim, cada Instituição de Ensino necessitará renovar e inovar seus projetos, suas metas, seus objetivos, visando acompanhar as constantes transformações pelas quais passam a sociedade contemporânea.

\subsection{Projeto de ensino}

Um projeto "na verdade é, a princípio, uma irrealidade que vai se tornando real, conforme começa a ganhar corpo a partir da realização de ações e consequentemente, das articulações desta", segundo Nogueira (2001, p 90 apud SILVA, 2017, p. 25). De outra forma,

Projeto é um esforço temporário realizado para criar um produto ou serviço único, diferente, de alguma maneira, de todos os outros produtos e serviços, com início e fim definidos, que utiliza recursos, é dirigido por pessoas e obedece a parâmetros de custo, tempo e qualidade (SANTOS et al., 2010, p. 27).

Projetos variam em tamanho e complexidade, mas não importa se grandes ou pequenos, simples ou complexos, todos os projetos podem ser mapeados pela estrutura de ciclo de vida, a seguir, na ordem cronológica: Iniciação; Planejamento; Execução; Encerramento e o Controle, que superpõe todas as fases (SANTOS et al., 2010), ilustrada na Figura 2. 
Figura 2- Ciclo de vida de um projeto

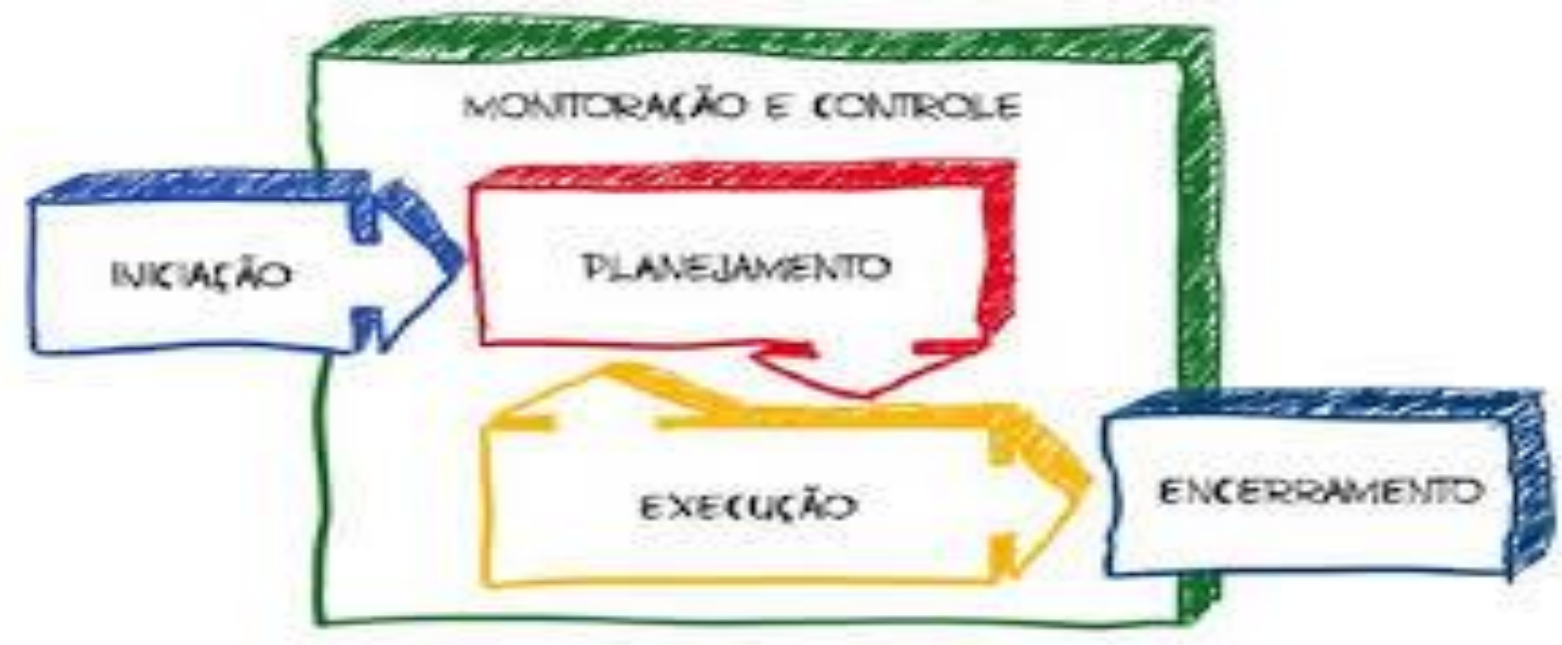

Fonte: próprio autor (2018).

Os requisitos principais nas fases de Iniciação e Planejamento são: identificar necessidades; estabelecer objetivos claros e alcançáveis; balancear demandas conflitantes de qualidade, escopo, tempo e custo; adaptar as especificações dos planos e da abordagem às diferentes preocupações e expectativas das diversas partes interessadas (GRANJA, 2012). Segundo Angélica (2018) na fase inicial são requeridas algumas ações importantes.

[...] envolve reuniões em que o coordenador seleciona o conteúdo do tema de estudo considerando o currículo, os objetivos gerais e específicos de cada disciplina. E propõe que cada professor apresente sugestões de como integrar e articular as disciplinas, e a partir disso estabelece-se a relação do tema com os objetivos de cada disciplina, os pontos em comum, e então discutem entre si para estabelecer quais serão as atividades que serão conduzidas de forma integrada" (ANGÉLICA, 2018, p.1).

$\mathrm{Na}$ fase inicial, Angélica (2018) destaca o surgimento do ator "coordenador pedagógico", que deve atuar de forma efetiva para o real entendimento da proposta, efetuando o realinhamento quando preciso e divulgando os resultados.

O coordenador pedagógico tem um papel fundamental como mediador do planejamento do projeto. E se tratando de um projeto interdisciplinar, é necessário que o coordenador discuta o tema do ponto de vista conceitual e prático, e não perca de vista o currículo da série em que se pretende aplicar o projeto (ANGÉLICA, 2018, p.1).

Em relação ao termo ensino, que para Ferreira (1999) é "uma forma sistemática de transmissão de conhecimentos utilizada pelos seres humanos para instruir e educar seus semelhantes", onde a finalidade do ensino é promover, nos educandos, a compreensão dos problemas que investigam (FERREIRA, 1999)

Compreender é ser capaz de ir além da informação dada, é poder reconhecer as diferentes versões de um fato e buscar explicá-las, além de propor hipótese sobre as consequências dessa pluralidade de pontos de vista (HERNÁNDEZ, 1998, p.86 apud SILVA, 2017, p. 30).

Segundo a teoria de William Glasser, os alunos aprendem $80 \%$ (oitenta por cento) efetivamente fazendo, em outras palavras, através das ações tais como: aplicar, utilizar e praticar, os alunos melhoram os índices de sua aprendizagem.

Segundo Borges (2018), projeto de ensino também poderia ser chamado de projeto didático ou projeto de trabalho, no entanto "deve ser entendido como uma proposta de organização e desenvolvimento dos conteúdos com participação dos alunos no processo de construção do conhecimento" (BORGES, 2018, p.1). 
Então, projetos de ensino, são projetos educacionais que visam promover melhorias no processo de ensino-aprendizagem, envolvendo uma ou mais disciplinas.

\section{METODOLOGIA}

Neste trabalho a metodologia principal utilizada foi a de Projeto, que está envolvida com métodos de coordenar e controlar alguns tipos de atividades complexas e dinâmicas, diferenciando-se muito da administração tradicional de atividades de rotina, segundo Malmegrin (2012). O foco deste estudo se limitou na implementação das fases de "Iniciação" e de "Planejamento" do PIDII. Segundo Angélica (2018) na fase iniciação são requeridas algumas ações importantes.

[...] envolve reuniões em que o coordenador seleciona o conteúdo do tema de estudo considerando o currículo, os objetivos gerais e específicos de cada disciplina. E propõe que cada professor apresente sugestões de como integrar e articular as disciplinas, e a partir disso estabelece-se a relação do tema com os objetivos de cada disciplina, os pontos em comum, e então discutem entre si para estabelecer quais serão as atividades que serão conduzidas de forma integrada" (ANGÉLICA, 2018, p.1).

Então, a fase iniciação do PIDII começou a partir da 1a Reunião, com uma pauta alinhada aos principais requisitos identificados por Granja (2012) e Angélica (2018), no qual os detalhes e resultados se encontram, neste trabalho, no próximo Item 4, atendendo às seguintes demandas: a identificação de uma situação-problema (uma oportunidade) para estruturação do projeto; definir o gestor do projeto e primeiras análises de viabilidade do mesmo para, em seguida executar a fase de "Planejamento" que envolvem vários processos a serem realizados, em especial, "desenvolver o curso de ação necessário para alcançar os objetivos para os quais o projeto foi criado" (SANTOS et al., 2010). No Quadro 1 são listados os processos por fases, além da identificação (cor: vermelha e com o símbolo \#) dos processos que não serão executados no PIDII.

Quadro 1 - Processos de projeto agrupados por fases

\begin{tabular}{|l|l|}
\hline \multicolumn{1}{|c|}{ Fases } & \multicolumn{1}{c|}{ Processos } \\
\hline Iniciação & $\begin{array}{l}\text { 1.\# Desenvolver o termo de abertura } \\
\text { 2. Identificar as partes interessadas }\end{array}$ \\
\hline 1.\# Desenvolver o plano de gerenciamento do projeto \\
2. Coletar os requisitos \\
3. Definir o escopo \\
4.\# Criar a estrutura analítica do projeto - EAP (WBS) \\
5. Definir as atividades \\
6. Sequenciar as atividades \\
7. Estimar os recursos das atividades \\
8. Estimar as durações das atividades \\
9. Desenvolver o cronograma \\
10.\# Estimar os custos \\
11.\# Determinar o orçamento \\
12.\# Planejar a qualidade \\
13.\# Desenvolver o plano de recursos humanos \\
14.\# Planejar as comunicações \\
15.\# Planejar o gerenciamento dos riscos \\
16.\# Identificar os riscos \\
17.\# Realizar a análise qualitativa dos riscos \\
18.\# Realizar a análise quantitativa dos riscos \\
19.\# Planejar as respostas aos riscos \\
20.\# Planejar as aquisições
\end{tabular}

Fonte: PMI/PMBOK- $4^{\text {a }}$ edição (2008). 
O projeto interdisciplinar requer um facilitador para integrar e articular diversas disciplinas de vários cursos do CEDERJ. Diante deste requisito a disciplina de "Introdução à Informática" se encaixa muito bem como um facilitador.

A disciplina de "Introdução à Informática" fundamenta-se numa abordagem tecnicista e é apresentada através de material didático disponível na Plataforma e de encontros presenciais obrigatórios realizados nos laboratórios de informática dos PAPs do CEDERJ. Nesses encontros os alunos têm oportunidade de praticar, com orientação do tutor presencial, o uso do computador, de seus aplicativos, da Plataforma e da internet de um modo geral.

Ao final da disciplina espera-se que o aluno seja capaz de interagir com os computadores para se comunicar, buscar informação utilizando a Internet, produzir conteúdo com apoio das NTDICs, em especial do LibreOffice, e saber utilizar todas as ferramentas (fórum, chat, wiki, atividades, questionários, etc.) disponíveis na Plataforma.

No que diz respeito às outras disciplinas dos cursos do CEDERJ inseridas no projeto, a despeito de serem usados recursos tecnológicos, o plano de aula a ser elaborado para implantação no ano seguinte, não se fundamenta numa abordagem tecnicista, nem pragmática, pois os recursos, apesar de terem um caráter tecnicista, demandam que o aluno elabore estratégias mentais (Teoria Cognitivismo) para as atividades teóricas e nas atividades práticas uma abordagem construtivista (Teoria Construtivismo).

Cabe ressaltar que, se trata de um Projeto piloto, ou seja, é um esforço temporário empreendido para testar a viabilidade de uma exclusiva solução apresentada, tanto que os processos de "Termo de abertura" (Fase de Iniciação) e o "Plano de gerenciamento do projeto" (Fase de Planejamento) não foram executados no PIDII.

Diante do contexto, foi escolhida a disciplina "Psicologia Organizacional" do $1^{\circ}$ período do Curso de Administração Pública (APU), para compor o projeto piloto por apresentar uma variedade de temas que são viáveis de serem implementados na administração do PAP de CGR, que possivelmente acarrete mudanças de melhorias na administração do Polo e, o mais importante, oportunize aos alunos do $1^{\circ}$ período do curso APU, durante sua formação acadêmica, participarem de um projeto interdisciplinar.

Outro ponto a ser esclarecido diz respeito à participação de somente um aluno do curso de Matemática, na equipe do Projeto piloto, atuando na função de monitor. Esta ação tem como objetivo viabilizar a criação de um Modelo de Acompanhamento e Avaliação, pelo Tutor Coordenador das Disciplinas Pedagógicas, a ser aplicado em períodos posteriores.

O pré-requisito para seleção do aluno que participará da equipe do projeto piloto foi ter sido aprovado nas disciplinas:

- Prática de Ensino I;

- Prática de Ensino II;

- Prática de Ensino III;

- Fundamentos da Educação I;

- Fundamentos da Educação II;

- Fundamentos da Educação III;

- Fundamentos da Educação IV;

- Estágio Supervisionado I. e

- Não ter cursado Informática no Ensino da Matemática.

O público-alvo do PIDII são os alunos do Curso de Administração Pública (APU) matriculados nas disciplinas de Psicologia Organizacional e Introdução à Informática.

A aplicação foi no PAP CEDERJ Campo Grande/RJ, mais especificamente, nos locais de realização das tutorias presenciais das disciplinas, de Psicologia Organizacional - "Sala de aula" e da Introdução à Informática - "Laboratório de informática". 


\section{ANÁLISE E DISCUSSÃO DOS RESULTADOS}

Neste item são apresentados os detalhes dos resultados Projeto e consecutivamente a análise e discussão dos subitens de mais relevância, que contribuíram para a realização do planejamento do projeto educacional, para disciplina de Introdução à Informática, utilizando as novas tecnologias digitais de informação e comunicação como instrumento na prática de atividades interdisciplinares.

Tema: Projeto de ensino interdisciplinar para EaD.

\section{Sujeitos envolvidos:}

- Equipe da Direção do Polo CGR - Diretora e Secretária;

- Gestor do Projeto;

- Tutores presenciais das disciplinas - Introdução à Informática e Psicologia Organizacional;

- Tutores Coordenadores - Curso de Administração Pública, Curso de Matemática e Disciplinas Pedagógicas e

- Alunos do Curso de Administração Pública (APU) matriculados nas disciplinas de Psicologia Organizacional e Introdução à Informática,

conforme consta na Tabela 1.

Tabela 1 - Controle de Matriculas

\begin{tabular}{|l|c|c|}
\hline \multicolumn{3}{|c|}{ INTRODUÇÃO À INFORMÁTICA - POLO CGR - 2018.2 } \\
\hline \multicolumn{1}{|c|}{ CURSO } & INSTITUIÇÃO & MATRICULADOS \\
\hline Administração Pública & UFF & 68 \\
\hline Ciências Biológicas (Licenciatura) & UFRJ & 64 \\
\hline Física (Licenciatura) & UFRJ & 78 \\
\hline Geografia (Licenciatura) & UERJ & 65 \\
\hline Matemática (Licenciatura) & UFF & $\mathbf{8 2}$ \\
\hline Tecnologia em Segurança Pública & UFF & 45 \\
\hline Turismo (Licenciatura) & UNIRIO & $\mathbf{5 5}$ \\
\hline \multicolumn{2}{|c|}{ TOTAL } & 457 \\
\hline
\end{tabular}

Fonte: SISTACAD (2018).

O total de alunos matriculados no curso de APU equivale, aproximadamente, à 15\% (quinze por cento) do total de alunos do PAP CGR no $2^{\circ}$ semestre de 2018.

Objetos do Projeto: Disciplinas e Avaliações à distancia

Disciplinas: com matrícula automática para os alunos calouros, ofertada no $1^{\circ}$ (primeiro) período dos cursos de nível superior do Consórcio CEDERJ: Introdução à Informática - disciplina obrigatória para todos os cursos. Psicologia Organizacional Curso de Administração Pública (APU).

Avaliações à distância: são previstas no ambiente virtual de aprendizagem Plataforma CEDERJ, duas avaliações à distância - AD1 e AD2 durante o período letivo, em todas as disciplinas ofertadas pelo Consórcio CEDERJ.

No documento intitulado: "Cronograma 2018.2 - parte 1", que contém o cronograma elaborado pela Universidade Federal Fluminense (UFF), é apresentada a data prevista para a realização/entrega da AD1 da disciplina "Introdução à Informática".

Então, no período de 2018.2 pode-se considerar, como referencial de parâmetros para os semestres seguintes, a AD1- Introdução à Informática e a AD1-Psicologia Organizacional, disponíveis na Plataforma CEDERJ. 
Na AD1- Introdução à Informática mais especificamente a atividade 1(um) da grade (Quadro 1), que tem grau igual a 2,0 (dois) pontos, para ser o ponto de ligação com a outra disciplina - "Psicologia Organizacional".

Aonde basta substituir o Tema, da Dissertação a ser produzida, sobre "Mobile Learning: A tecnologia móvel na Educação", para um tema que aborde a importância da Psicologia Organizacional para a Gestão Pública no Polo de Apoio Presencial do CEDERJ CGR, como por exemplos: "A contribuição da Teoria da Motivação para gestão do PAP".

Quadro 2 - Atividade 1 da AD1 de Introdução à Informática

\begin{tabular}{|l|l|c|}
\hline \multicolumn{1}{|c|}{ ATIVIDADES } & Valor em Pontos \\
\hline 1 & $\begin{array}{l}\text { Utilizar como tema da Dissertação: "Mobile Learning: A } \\
\text { tecnologia móvel na Educação". Comente sobre } \\
\begin{array}{l}\text { Ambientes de Aprendizagem e Segurança neste } \\
\text { contexto. }\end{array}\end{array}$ & $\mathbf{2 , 0}$ \\
\hline
\end{tabular}

Fonte: Adaptado pelo autor a Plataforma CEDERJ (2018).

Acarretando assim uma pequena mudança (identificada com a cor verde e as setas de sinalização) na proposta da AD1 da disciplina Psicologia Organizacional, no ambiente virtual de aprendizagem, conforme ilustra a Figura 3.

Figura 3 - AD1 de APU no AVA

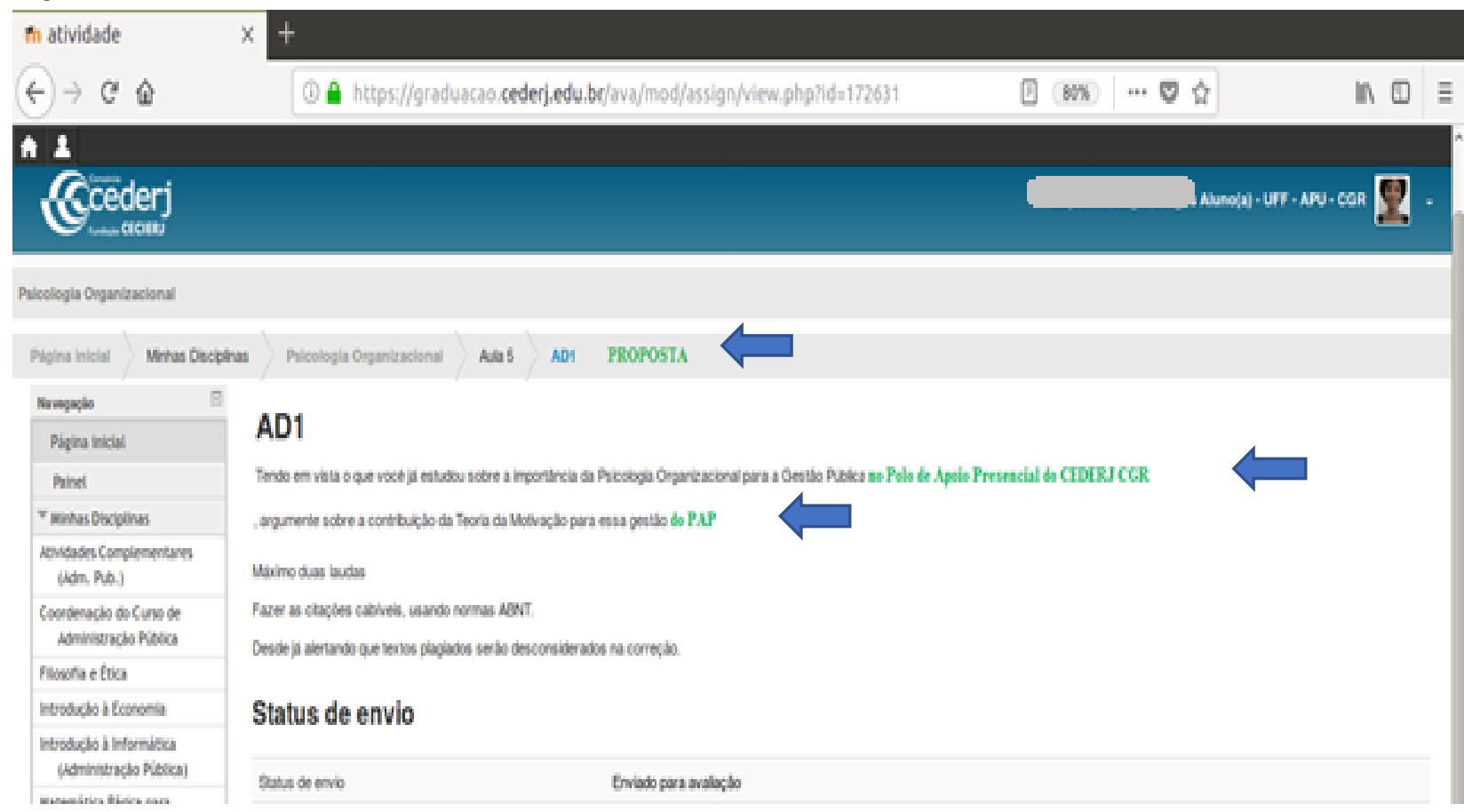

Fonte: Adaptado pelo autor a Plataforma CEDERJ (2018).

A "Proposta da Nova AD1", que se encontra ilustrada no Quadro 1, documento "AD1 - Xo semestre de 201Y", teve suas orientações, objetivos, grade das atividades e pontuação, elaboradas em conformidade com os currículos, do curso APU, mais especificamente das disciplinas:

"Introdução à Informática" - atendendo a parte da ementa no que tange a "possibilitar ao estudante identificar o computador como importante ferramenta de trabalho", bem como," desenvolver proficiência no setor da Internet e no uso de editores de textos".

"Psicologia Organizacional" - atendendo principalmente em "possibilitar o uso dos conhecimentos adquiridos" em sua vida acadêmica e "a trabalhar com os alunos a aplicabilidade dos conceitos" por meio de um estudo de caso, no qual se refere ao contexto da administração do PAP de CGR. 


\begin{tabular}{|c|c|c|}
\hline \multicolumn{3}{|c|}{$\begin{array}{l}\text { Fundacialo Centro de Cienclas e Educacia Superior a Distancia do Estado do Rao de Janeiro } \\
\text { Centro de Educacabo Superior a Distancia do Estado do Plo de Janeiro }\end{array}$} \\
\hline \multicolumn{3}{|c|}{$\begin{array}{c}\text { AD1 - Xo SEMESTRE de 201Y } \\
\text { INTRODUÇÃO À INFORMÁTICA / PSICOLOGIA ORGANIZACIONAL (APU/UFF) }\end{array}$} \\
\hline & ATIVIDADES & Pontos \\
\hline 1 & $\begin{array}{l}\text { Utilizar como tema da Dissertação: "A importância da Psicologia Organizacional } \\
\text { para a Gestão Pública". Aborde sobre a contribuição da Teoria da Motivação para a } \\
\text { Gestão do Polo de Apoio Presencial do CEDERJ Campo Grande -RJ. }\end{array}$ & 2,0 \\
\hline 2 & Título com fonte Time New Roman Tamanho 14 em itálico & 0,5 \\
\hline 3 & $\begin{array}{l}\text { Texto com fonte Time New Roman Tamanho } 12 \text { com subtítulos com a mesma fonte com } \\
\text { tamanho } 13 .\end{array}$ & 0,5 \\
\hline 4 & $\begin{array}{l}\text { Uma Tabela com pelo menos } 4 \text { linhas e } 2 \text { colunas referente ao assunto. Esta tabela } \\
\text { deve estar referenciada no texto. }\end{array}$ & 0,5 \\
\hline 5 & $\begin{array}{l}\text { Uma Imagem referente ao assunto com legenda, com a referencia do site de onde foi } \\
\text { copiada, no formato de hiperlink. Essa imagem deve estar referenciada no texto. A } \\
\text { imagem não pode ter mais que } 1 / 4 \text { da página. }\end{array}$ & 0,5 \\
\hline 6 & Texto em duas colunas com alinhamento justificado entre as margens. & 0,5 \\
\hline 7 & Uma nota de rodapé explicativa de algum elemento do texto. & 0,5 \\
\hline 8 & Espaçamento entre linhas $1,0 \mathrm{~cm}$ & 0,5 \\
\hline 9 & Sua dissertação deve possuir no máximo 3 (três) laudas & 1,0 \\
\hline 10 & $\begin{array}{l}\text { Cabeçalho com o título do trabalho (opcional) e logomarca CEDERJ (obrigatória) } \\
\text { aparecendo no alto de cada página do documento. }\end{array}$ & 1,0 \\
\hline 11 & $\begin{array}{l}\text { Coloque no rodapé do lado direito da página utilizando NUMERAÇÃO AUTOMÁTICA } \\
\text { DE PÁGINA. Como exemplo: "pág.: 2" (sem aspas), onde está é da segunda página do } \\
\text { documento. }\end{array}$ & 0,5 \\
\hline 12 & $\begin{array}{l}\text { Lista com marcadores de numeração com as referencias da pesquisa (em conformidade } \\
\text { com as Normas ABNT), no subtítulo "Referências", no final do texto. }\end{array}$ & 1,0 \\
\hline 13 & Trabalho salvo com a extensão correta (.odt) & 0,5 \\
\hline 14 & Exporta o texto para formato .pdf & 0,5 \\
\hline & Total de Pontos & 10,0 \\
\hline
\end{tabular}

Fonte: Adaptado pelo autor a Plataforma CEDERJ (2018).

O cronograma do PIDII está descrito em detalhe, na Tabela 2, a seguir, onde constam todas as ações a serem realizadas dentro do prazo do semestre acadêmico, além de elencar os recursos: pessoal, material, dentre outros, para que o projeto seja implementado com sucesso.

Cabe ressaltar que a principal mudança em relação a Plano de aula (item 4.2.3 da Tabela 2) ocorre na disciplina "Psicologia Organizacional", que introduz no roteiro das atividades práticas, a entrevista junto à equipe Administrativa do Polo, agendada e apoiada pelo Tutor presencial, visando possibilitar ao aluno a coleta de dados sobre o tema da nova AD1 - A Gestão Pública no Polo de Apoio Presencial do CEDERJ CGR, como foco sobre "A contribuição da Teoria da Motivação para gestão do PAP”.

Tabela 2 - Cronograma do Projeto Interdisciplinar Piloto

\begin{tabular}{|l|c|c|c|c|c|}
\hline \multicolumn{5}{|c|}{ Projeto Interdisciplinar Piloto: Disciplina Introdução à Informática } \\
\hline 4. AÇõES & RESPONSÁVEL & PRAZO & \multicolumn{3}{|c|}{ RECURSOS } \\
\cline { 4 - 6 } & Pessoal & Material & Outros \\
\hline $\begin{array}{l}\text { 4.1 Realizar 1a Reunião - projeto } \\
\text { interdisciplinar }\end{array}$ & Coordenador Projeto & $\begin{array}{c}1 \text { dia } \\
10 \text { mês }\end{array}$ & 7 & $\begin{array}{l}\text { Notebook e } \\
\text { Data show }\end{array}$ & 4 horas \\
\hline
\end{tabular}




\begin{tabular}{|c|c|c|c|c|c|}
\hline 4.1.1 Apresentar a Equipe do Projeto & $\begin{array}{c}\text { Coordenador Projeto } \\
\text { Coordenador } \\
\text { Pedagógico } \\
\text { Tutor Coord. APU } \\
\text { Tutor de Intr. à } \\
\text { Informática } \\
\text { Tutor de Psicologia } \\
\text { Organizacional } \\
\text { Aluno do curso } \\
\text { Matemática }\end{array}$ & $\begin{array}{l}1 \text { dia } \\
1^{1} \text { mês }\end{array}$ & 7 & $\begin{array}{l}\text { Notebook e } \\
\text { Data show }\end{array}$ & \\
\hline $\begin{array}{l}\text { 4.1.2 Apresentar para equipe a } \\
\text { proposta do projeto interdisciplinar } \\
\text { da disciplina de Introdução à } \\
\text { Informática e o curso de } \\
\text { Administração Pública }\end{array}$ & Coordenador Projeto & $\begin{array}{l}1 \text { dia } \\
1^{1} \text { mês }\end{array}$ & 1 & $\begin{array}{l}\text { Notebook e } \\
\text { Data show }\end{array}$ & 2 horas \\
\hline $\begin{array}{l}\text { 4.1.3 Identificar os objetivos gerais e } \\
\text { específicos das disciplinas - APU }\end{array}$ & Tutor Coordenador APU & $\begin{array}{l}1 \text { dia } \\
1 \stackrel{0}{\text { mês }}\end{array}$ & 1 & $\begin{array}{l}\text { Notebook, } \\
\text { Data show e } \\
\text { Ementas }\end{array}$ & 2 horas \\
\hline $\begin{array}{l}\text { 4.2 Realizar } 2^{a} \text { Reunião - projeto } \\
\text { interdisciplinar }\end{array}$ & Coordenador Projeto & $\begin{array}{l}1 \text { dia } \\
1^{\circ} \text { mês }\end{array}$ & 7 & $\begin{array}{l}\text { Notebook, } \\
\text { Plataforma e } \\
\text { Ementas } \\
\end{array}$ & 5 horas \\
\hline $\begin{array}{l}\text { 4.2.1 Apresentar o tema e os } \\
\text { conteúdos considerando o currículo } \\
\text { do curso de Administração Pública }\end{array}$ & Tutor Coordenador APU & 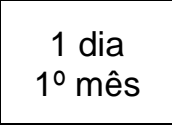 & 1 & $\begin{array}{l}\text { Notebook, } \\
\text { Data show e } \\
\text { Ementas }\end{array}$ & 1 hora \\
\hline $\begin{array}{l}\text { 4.2.2 Estabelecer a relação do tema } \\
\text { com os objetivos das duas } \\
\text { disciplinas }\end{array}$ & $\begin{array}{l}\text { Coordenador } \\
\text { Pedagógico }\end{array}$ & 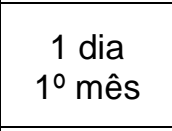 & 7 & $\begin{array}{l}\text { Notebook e } \\
\text { Data show }\end{array}$ & 2 horas \\
\hline $\begin{array}{l}\text { 4.2.3 Estabelecer quais serão as } \\
\text { atividades que serão conduzidas de } \\
\text { forma integrada }\end{array}$ & $\begin{array}{l}\text { Coordenador } \\
\text { Pedagógico }\end{array}$ & 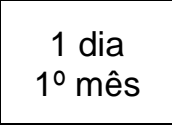 & 7 & $\begin{array}{l}\text { Notebook e } \\
\text { Data show }\end{array}$ & 2 horas \\
\hline $\begin{array}{l}\text { 4.3 Criar a agenda das atividades - } \\
\text { Plano de Aulas/Tutorias }\end{array}$ & $\begin{array}{l}\text { Coordenador Projeto } \\
\text { Tutor Coord. APU } \\
\text { Tutor de Intr. à } \\
\text { Informática }\end{array}$ & $\begin{array}{l}2 \text { dias } \\
1 \stackrel{0}{\text { mês }} \\
2019\end{array}$ & 7 & $\begin{array}{l}\text { Notebook, } \\
\text { Plataforma e } \\
\text { Ementas }\end{array}$ & 2 horas \\
\hline $\begin{array}{l}\text { 4.3.1 Divulgar a agenda das } \\
\text { atividades }\end{array}$ & $\begin{array}{l}\text { Coordenador Projeto } \\
\text { Aluno do curso } \\
\text { Matemática }\end{array}$ & $\begin{array}{c}1 \text { dia } \\
1 \text { o mês }\end{array}$ & 2 & $\begin{array}{l}\text { Notebook e } \\
\text { Plataforma }\end{array}$ & 1 hora \\
\hline $\begin{array}{l}\text { 4.4 Implementar atividades práticas } \\
\text { no Laboratório de Informática }\end{array}$ & $\begin{array}{l}\text { Tutor de Intr. à } \\
\text { Informática } \\
\text { Psicologia } \\
\text { Organizacional }\end{array}$ & $\begin{array}{l}6 \text { meses } \\
\text { Semestre } \\
2019\end{array}$ & 3 & $\begin{array}{l}\text { Laboratório } \\
\text { de } \\
\text { Informática e } \\
\text { Plataforma }\end{array}$ & $\begin{array}{l}6 \text { horas/ } \\
\text { mês }\end{array}$ \\
\hline $\begin{array}{l}\text { 4.4.1 Implementar as Avaliações } \\
\text { práticas. }\end{array}$ & $\begin{array}{l}\text { Tutor de Intr. à } \\
\text { Informática } \\
\text { Psicologia } \\
\text { Organizacional }\end{array}$ & $\begin{array}{l}1 \text { semana } \\
3^{\circ} \text { mês } \\
6^{\circ} \text { mês }\end{array}$ & 3 & $\begin{array}{l}\text { Laboratório } \\
\text { de } \\
\text { Informática e } \\
\text { Plataforma }\end{array}$ & $\begin{array}{l}2 \text { horas } \\
\text { /tutoria }\end{array}$ \\
\hline $\begin{array}{l}\text { 4.4.2 Acompanhar os resultados das } \\
\text { Avaliações. }\end{array}$ & $\begin{array}{c}\text { Tutor Coordenador APU } \\
\text { Aluno do curso } \\
\text { Matemática }\end{array}$ & $\begin{array}{l}5 \text { dias } \\
3^{0} \text { mês } \\
6^{0} \text { mês }\end{array}$ & 2 & Plataforma & 1 hora \\
\hline $\begin{array}{l}4.5 \text { Identificar e registrar as } \\
\text { melhorias a serem realizadas no } \\
\text { Projeto Interdisciplinar }\end{array}$ & $\begin{array}{l}\text { Coordenador } \\
\text { Pedagógico } \\
\text { Coordenador Projeto } \\
\text { Aluno do curso } \\
\text { Matemática } \\
\end{array}$ & $\begin{array}{l}2 \text { dias } \\
6^{0} \text { mês }\end{array}$ & 3 & Notebook & 8 horas \\
\hline
\end{tabular}

Fonte: Próprio autor (2018).

\section{CONSIDERAÇÕES FINAIS}

A fase de planejamento elaborada do PIDII tem como ponto focal a utilização das NTDICs durante as Tutorias Práticas da disciplina de Introdução à Informática, no PAP 
CGR, por ser um possível instrumento eficiente e eficaz na prática de atividades interdisciplinares. Assim tende-se a melhorar o desempenho na vida cotidiana e acadêmica de cursistas e tutores. As atividades planejadas para as tutorias práticas atendem a demanda da promoção da capacitação do uso das NTDICs que auxilie a produzir e gerenciar conhecimentos; consolidando o aprendizado dos conceitos adquiridos e provocando a experiência de propor mudanças de melhorias na administração do PAP.

Em especial, para os cursistas, as atividades planejadas no PIDII, possibilita o desenvolvimento e/ou aprimoração de características pessoais e profissionais, como adaptação para as mudanças e a fluência tecnológica e linguística. $E$ das capacidades de assimilação; reflexão; criatividade; clareza de raciocínio; motivação e foco, que tem uma relação de desempenho e eficiência quando se implementa uma rotina individual de estudos, com ênfase no grau de dedicação, compromisso, disciplina e organização.

O avanço das NTDICs provocou grandes desafios à educação, como as dinâmicas sócio-técnicas, que têm nos postos a refletir sobre outros modos de saber/fazer e em novas práticas, que enfatizam os processos educacionais em contextos tecnológicos: as tecnologias como ferramentas de ensino-aprendizagem e as tecnologias aplicadas à sociedade. Salientando o contexto da responsabilidade que a Instituição de Ensino de hoje tem em formar cidadãos críticos, criativos, capazes de resolver os problemas de um mundo globalizado e altamente competitivo.

Neste contexto, dentre os agentes envolvidos no processo educativo, destaca-se a importância da participação do professor-educador (tutores), agente condutor, elo mediador na troca de saberes para formação social e cidadã dos indivíduos. No sistema educacional brasileiro o desafio está em fazer os educadores (professores e tutores) participarem ativamente, pois o que mais encontramos é a desvalorização do educador, quer seja pela falta de acesso à formação continuada, pelos baixos salários que o obriga a trabalhar em várias unidades de ensino ou, até mesmo, realizar outra atividade para completar a renda, dificultando ou impossibilitando a dedicação necessária do mesmo. Cabe ressaltar que, as atuais condições sociais de produção têm exigido do professorado um necessário e constante aprimoramento profissional.

É fato que para o desenvolvimento sólido de uma sociedade se faz necessário, indubitavelmente, a formação dos profissionais que atuam em qualquer modalidade e, em especial, nos que atuam junto à formação humana. A formação do educador requer, então, ambiente com condições adequadas e apoio dos seus gestores, pois sua formação deve se desenvolver como um contínuo, marcada pela resiliência, pelo entusiasmo e pela predisposição em abraçar a atividade docente com curiosidade, energia, capacidade de renovação e de luta contra a rotina.

Por fim, há de se enfatizar que, a execução das fases "Iniciação" e de "Planejamento" do PIDII transcorreram perfeitamente dentro do prazo estipulado (dois meses), graças ao engajamento dos colaboradores da equipe do PIDII, e em relação ao que tange à análise do contexto da utilização das NTDICs como instrumento eficiente e eficaz na prática de atividades interdisciplinares, visando o melhor desempenho na vida cotidiana e acadêmica de alunos e tutores, principal objetivo do PIDII, somente será possível qualquer análise e conclusão após as fases de "Execução" e "Encerramento" do PIDII no PAP do CEDERJ, em CGR - RJ, o que depende da avaliação do projeto e respectiva aprovação pela Fundação CECIERJ - Centro de Ciências e Educação Superior a Distância do Estado do Rio de Janeiro.

Contudo diante das experiências vividas durante o curso em TFPS e na realização do PIDII, é perceptível que o maior desafio da educação na atualidade está na formação continuada de professores, sejam eles da geração de "nativos digitais" ou não (PRENSKY, 2001), pois um "professor inovador" (que aprende em rede - ciberespaço da formação, sem 
hierarquias, cooperativamente, colaborativamente e de forma auto-organizada) deve ser consciente de seu tempo e dos recursos à sua disposição, sempre com visão emancipadora, em busca de mudança, ávido por refletir sobre sua práxis, ciente de sua responsabilidade para a conquista da cidadania, sendo todos esses requisitos essenciais a serem considerados para sua capacitação, além da própria habilidade em manipular as novas tecnologias digitais e virtuais. Esse conjunto certamente pode reforçar o poder multiplicador das tecnologias sociais.

\section{REFERÊNCIAS}

ANGÉLICA, M. Interdisciplinaridade: O que é, conceitos e como aplicar na educação. Ensino Guia de Educação. Disponível em:

https://canaldoensino.com.br/blog/interdisciplinaridade-o-que-e-conceitos-e-como-aplicarna-educacao. Acesso em: 10 jul. 2020.

BERGUE, S. T. Cultura e mudança organizacional. 2. ed. reimp. - Florianópolis: Departamento de Ciências da Administração / UFSC, 2012.

BORGES, G. L. de A. Orientações gerais para o desenvolvimento do Projeto de Ensino. UNESP/Botucatu. UNIVESP. Disponível em: https://docente.ifrn.edu.br/liviasantos/disciplinas/projeto-integrador/material-comorientacoes-para-desenvolvimento-de-projetos-de-ensino. Acesso em: 10 jul. 2020.

BRASIL. Lei no 9.394, de 20 de dezembro de 1996. Lei de Diretrizes e Bases da Educação Nacional. Diário Oficial da União, Brasília, DF, 24 dez. 1996. Disponível em: . Acesso em: 10 jul. 2020.

CECIERJ - Centro de Ciências e Educação Superior a Distância do Estado do Rio de Janeiro. Site do CECIERJ. Disponível em: https://www.cecierj.edu.br/ Acesso em: jul. 2020.

COSTA, V. B. A interdisciplinaridade no ensino de Ciências Humanas e Sociais: dos limites às possibilidades. Itinerarius Reflectionis - Revista Eletrônica do Curso de Pedagogia do Campus Jataí, Universidade Federal de Goiás - UFG, v.11, n.1, 2015. Disponível em: . Acesso em: jul. 2020.

FAZENDA, I. C. A. A Interdisciplinaridade: História, teoria e Pesquisa. São Paulo: Papirus, 1994.

FERREIRA, A.B.de.H. Novo Dicionário Aurélio da Língua Portuguesa com CD - ROM. Positivo Editora. 1999.

FNDE - Fundo Nacional de Desenvolvimento da Educação. Resolução CD/FNDE № 26, de 5 de junho de 2009. Disponível em: http://www.fnde.gov.br/acesso-ainformacao/institucional/legislacao/item/3320-resolu\%C3\%A7\%C3\%A3o-cd-fnden\%C2\%BA-26-de-5-de-junho-de-2009. Acesso em: jul. 2020.

GRANJA, S. I. B. Elaboração e avaliação de Projetos. $2^{\underline{a}}$ edição reimp. - Florianópolis: Departamento de Ciências da Administração / UFSC; [Brasília]: CAPES: UAB, 2012. 
LIBREOFFICE. O que é o LibreOffice. The Document Foundation. Disponível em: https://pt-br.libreoffice.org/descubra/libreoffice/. Acesso em: jul. 2020.

MALMEGRIN, M. L. Gestão Operacional. $2^{2}$ edição reimp. - Florianópolis: Departamento de Ciências da Administração / UFSC; [Brasília]: CAPES: UAB, 2012.

MEC - Ministério da Educação Secretaria de Educação a Distância. PORTARIA № 153, DE 12 DE JULHO DE 2018. Agosto de 2007. Disponível em:

http://www.imprensanacional.gov.br/materia//asset_publisher/Kujrw0TZC2Mb/content/id/31544661/do1-2018-07-16-portaria-n-153-de12-de-julho-de-2018-31544633. Acesso em: jun. 2020.

MOUSINHO, S. H. A interdisciplinaridade ao alcance de todos. Disponível em: http://educacaopublica.cederj.edu.br/revista/artigos/a-interdisciplinaridade-ao-alcance-detodos. Acesso em: jun. 2020.

PINHEIRO, N. A. M.; SILVEIRA, R. M. C. F.; BAZZO, W. A.. Ciência, Tecnologia e Sociedade: a relevância do enfoque CTS para o contexto do ensino médio. Ciência e Educação. 2007, v. 13, n. 1, p. 71-84.

POMBO, O. Interdisciplinaridade e integração dos saberes. 2006. Disponível em: Acesso em: jun. 2020.

PRENSKY, M. Digital Native, digital immmigrants. Digital Native immigrants. On the horizon, MCB University Press, v. 9, n. 5, October, 2001. Disponível em:

http://www.marcprensky.com/writing/Prensky\%20-

\%20Digital\%20Natives,\%20Digital\%20Immigrants\%20-\%20Part1.pdf. Acesso em: jun.2020.

PROJECT MANAGEMENT INSTITUTE (PMI). Guide to the project management body of know ledge: PMBOK guides. 4. ed. s.I., 2008.

RIBAS, J. C. C.; MOREIRA, B. C. M.; CATAPAN, A. H. Construindo referenciais de qualidade para uma gestão eficaz no sistema Universidade Aberta do Brasil: $O$ ambiente virtual de ensino-aprendizagem e a capacitação dos coordenadores de polo de apoio presencial. 2011. Disponível em:. Acesso em: jun. 2020.

SANTOS, C. M.; BRITO, A. M. F.; BARUQUE, C. B.; BARUQUE, L. B. Fundamentos de Gestão de Projetos de Tecnologia da Informação. v. 1 /- Rio de Janeiro: Fundação CECIERJ, 2010.

\section{SILVA, A. M. de P. A. Interdisciplinaridade e Integração Curricular por meio da}

Pedagogia dos Projetos - Um desafio para os docentes. 2017. Disponível em: https://repositorio.unifei.edu.br/xmlui/bitstream/handle/123456789/729/dissertacao_alves_ e_silva_2017.pdf?sequence=1\&isAllowed=y. Acesso em: 10 jul. 2020.

TECNOLOGIAS TFPS. Experiências em processos de formação e procedimentos tecnológicos - Polo Resende. Disponível em:

https://padlet.com/tfps2018/gca5bbnaug4v. Acesso em: jun. 2020. 
UAB/CAPES - Sitio da Universidade Aberta do Brasil. Disponível em: . Acesso em: jun. 2020.

UMBELINO, M.; ZABINI, F. O. A importância da interdisciplinaridade na formação do docente. Seminário Internacional de Educação Superior. 2014. Disponível em: https://uniso.br/publicacoes/anais_eletronicos/2014/1_es_formacao_de_professores/44.p df. Acesso em: jun. 2020.

VILLARDI, R.; OLIVEIRA, E. Tecnologia na educação: uma perspectiva sociointeracionista. Rio de Janeiro: Dunya, 2005.

XAVIER, M. A. G. A Gestão Pública em Polo de Apoio Presencial do Sistema da Universidade Aberta do Brasil: Estudo de caso no Polo de Apoio Presencial em Resende. Revista: EAD em Foco, v. 6, p. 242, 2016. Disponível em: http://eademfoco.cecierj.edu.br/index.php/Revista/article/view/242/170 Acesso em: jun. 2020.

XAVIER, M. A. G.; CARVALHO, A. C. de; BRANDÃO, L. P.; FREITAS, V. G. G. A relação entre a formação dos professores e o ambiente virtual de aprendizagem. RECITERevista Carioca de Ciência, Tecnologia e Educação, v. 4, n. 2, 2019. Disponível em: https://doi.org/10.17648/2596-058X-recite-v4n2-1. Acesso em: jun. 2020.

i A Educação a distância é uma modalidade de ensino que amplia as possibilidades do saber, criando e potencializando competências de uma sociedade norteada pela informação (XAVIER, 2016).

ii Informações foram extraídas do Edital no 001/2018 - Seleção pública destinada à concessão de bolsas e formação de cadastro de reserva de tutores presenciais para atuação nos cursos de graduação. Disponível em: >. Acesso em: jun. 2020. 